ultra-high-frequency range. T'here is no theoretical reason why such a small absorption should not take place and Dr. Whiffen offered one possible explanation. M. Magat discussed the absorption of various organic materials in the centimetre range. Aliphatic alcohols exhibit two distinct dispersion regions, both of which are due to relaxation mechanisms because both are strongly temperature-dependent. F. J. Lehany sum marized the results obtained in the National Stand. ards Laboratory, Sydney, on crystalline secondary alcohols. B. Szigeti discussed the theory of molecular torsion in long-chain ketones and showed that this mechanism leads to a polarizability which is very large compared with the values of 'vibrational' or 'atomic' polarizability encountered in most other substances. W. G. Oakes said that both crystalline rubber and polythene exhibit two distinct relaxation mechanisms. If the crystallinity of rubber is reduced, one of the absorption maxima disappears. E. Rushton discussed the dielectric properties of liquid silicones.

The third day started with two talks on solid hydrogen chloride and hydrogen bromide, by $\mathbf{E}$. Bauer and J. G. Powles. In the lowest-temperature phase, hydrogen bromide shows two dispersion regions due to relaxation mechanisms, and one of these disappears at the first transition. Prof. Bauer thinks that in the lowest-temperature phase hydrogen bromide should be considered as 'anti-ferro-electric'. In the same phase there is a large difference between the dielectric behaviour of hydrogen bromide and deuterium bromide, and Dr. Powles explained this by assuming that at very low temperatures polariza. tion can take place in the former by means of a tunnel effect.

R. Freymann demonstrated that dielectric measurements can distinguish between adsorbed and chemically-bound water in solids. V. Daniel discussed experiments which showed that very small amounts of impurities, in particular water, can have a very large effect on the dielectric properties near the melting point. C. Dodd and G. N. Roberts said that the dielectric properties of $a$ supercooled liquid exhibit a change at the melting point. J. J. O'Dwyer derived a phenomenological relation between the polarization and the electric field for very strong fields when the relationship is not linear. H. Pelzer spoke on the energy loss and effective mass of slow electrons in ionic crystals.

The discussion on dielectric breakdown was opened by $\mathrm{S}$. Whitehead, who reviewed the influence of theoretical developments on engineering practice. He stated that from the practical point of view little interest can be attached to the further improvements of the best dielectrics ; much more advantage can be gained from the improvement of those dielectrics which are not very good at present. K. A. Macfadyen reported measurements on the breakdown of liquids and concluded that liquids do not conform to the existing breakdown theories which have been developed for crystals or amorphous substances. Talking on breakdown in solids, W. Franz doveloped the view that several existing theories can account for the known experimental facts. H. B. Callen, on the other hand, maintained that preference can be given to one particular theory which alone is able to explain the fact that the breakdown path favours certain crystallographic directions. The conclusions of both Prof. Franz and Dr. Callen were contradicted by Prof. Fröhlich, and Dr. Callen's arguments were also criticized by Dr. Huang. With this discussion the conference came to an end.
Prior to the Conference there was a three-day 'summer school' on the theory of dielectrics. The lecturers were Prof. H. Fröhlich and Dr. B. Szigeti, and one lecture was also given by Dr. J. G. Powles. The school was arranged for the benefit of experimental physicists with theoretical interests.

B. SZIGETI

\section{BOSE INSTITUTE, CALCUTTA} ANNIVERSARY MEETING

7 HE thirty-fourth anniversary of the Bose Institute was celebrated on November 30, when Prof. P. C. Mahalanobis, statistical adviser to the Cabinet, Government of India, gave the thirteenth Acharya Jagadish Chandra Bose Memorial Lecture. His subject was "Statistical Methods in Relation to National Development". His Excellency Dr. H. C. Mookherjee, Governor of West Bengal, presided over the meeting.

In presenting his annual report, Dr. D. M. Bose, director of the Institute, referred to its severe loss through the death of Lady Abala Bose, , widow of Acharya Bose, and of Prof. N. C. Nag, who served as assistant director and was a trusted colleague of the founder. Speaking of Lady Bose, Dr. D. M. Bose said that those on whom the direction of the Bose Institute devolved after the death of the founder will recall with gratitude the help they constantly received from Lady Bose, by her advice, and by her presence at Council and governing body meetings. He then gave a short sketch of the life of Lady Bose and of the fifty years of her eventful married life, which terminated with the death of Acharya Bose in 1937. "It would be rare in any country," he said, "to find such instances of two gifted and strong personalities with similar ideals and in many ways with complementary characters, united in matrimony and fully utilizing their inborn gifts to the service of their country and of their fellow beings. One of them was temperamental, artistic, with a romantic imagination, dreaming of the resuscitation of the achievements of ancient India as exemplified in Taxila, Nalanda and Ajanta, interested more in putting concrete shape to his ideas rather than in individuals; the other calm and unruffled, with intuitive wisdom and human sympathy, which deepened with age and experience. After the death of her husband a now chapter of her life commenced." He also described her work on behalf of widows and other distressed women of Bengal through the institutions founded and managed by her for a period of thirty years.

Dr. Bose then gave an account of the principal sources of income of the Institute, the total income of which during the present year is expected to exceed Rs. 300,000. The Institute has received during the past three years a total non-recurring grant of about Rs. 300,000, of which Rs. 180,000 was contributed by the Govermment of India and Rs. 120,000 by the Sir J. C. Bose Trust No. 1. This amount has been spent principally in the erection and equipment of a new laboratory built on the top of the Institute lecture hall, and in the purchase of equipment for the workshop and laboratories.

The Government of West Bengal has agreed to acquire for the Falta' Agricultural Experiment Station of the Bose Institute about 58 bighas of Khas Mahal land at an estimated cost of about Rs. 48,000 , of which the Government will contribute 
one-third and the balance will be met out of a donation from the Sir J. C. Bose Trust No. 1. Plans have been approved for the erection of a two-storied structure of floor area about $3,500 \mathrm{sq}$. $\mathrm{ft}$. at the south-west corner of the Institute quadrangle, at an estimated cost of Rs. 80,000, of which half has been given by the Sir J. C. Bose Trust No. 1, and the Central Government has been asked to contribute an equal amount. This building will house the workshop and the library, which have outgrown their present accommodation. At the Mayapuri Research Station, Darjeeling, a glass-house and a microbiological laboratory have been fitted up for the study of potato virus disease and for the survey of the distribution, at different altitudes, of soil micro-organisms in cultivated and virgin soils of the Darjeeling district.

Two research fellows recently returned from the United States and Canada are constructing apparatus for cosmic ray investigations, which will be taken to Darjeeling next spring for experiments at high altitudes. These include a large pressure ionizaticn chamber, counter telescopes, a large rectangular Wilson chamber, and a small Wilson chamber placed in the field of a medium-sized electromagnet consuming $25 \mathrm{~kW}$.

The cytological and mutagenic action of X-rays, ultra-violet rays, ultrasonic radiation, as well as of different chemical reagents, is being investigated. As reported previously, improved mutants of jute have been obtained with X-ray treatment ; recently plants grown from irradiated Sesamum seeds appear to give a promising yield of oil-seeds. The effect of penicillin in inhibiting the growth of soil organisms and producing cytological effects on plant colls has been studied. Pericillin has been found to prevent the transformation of tadpoles into frogs; tadpoles kept for some time in a dilute penicillin solution and then transformed to their normal habitat in water have continued to grow and increase in size for six months without metamorphosing into frogs.

\section{OVERSEAS FOOD CORPORATION}

7 HE report of the Overseas Food Corporation*, to which are appended the accounts for the year ended March 31, 1951, some notes on land-use surveys and the report of the Scientific Department for the crop year 1949-50, records steady progress towards the decentralization foreshadowed in the previous report and rapid implementation of the recommendations of the Kongwa Working Party's report of September 1950 .

Before the 1950-51 planting season, agricultural operations were reduced to the four comparatively small farms recommended. Management of smaller acreages by the more experienced farmers and a better distribution of rainfall in the critical months of January and February demonstrated the potential of the area more favourably. Land clearing in Urambo was virtually completed at 65,000 acres, and full-scale farming established with 45,000 acres planted. Clearing in the Southern Province was limited to the 60,000 acres recommended as a first stage in the revised plan presented to Parliament in January 1951, and all money advanced to the Corporation for the East African Groundnut Scheme up to March 31, 1951, has been written off. Hand labour is being substituted for the mechanical processes of piling the felled trees and excavating stumps.

* Overseas Food Corporation. Annual Report and Statement of Accounts for the Year ended 31st March 1951. Pp. iv +82. (London :
H.M. Stationery Office, 1951.) 3s. net.
The notes on land-use surveys indicate the contribution made by the Corporation to the technique involved ; waste of much labour in clearing unsuitable land both in Urambo and the Southern Province has been saved by land-use surveys and soil conservation surveys. Observations in all areas confirmed the view that consistent and informed consideration must be given to the intricate problems of the loss of soil and soluble plant foods through surface wash and the leaching of the principal plant foods during periods of early and high-intensity rainfall. Demarcation technique has been improved by a method developed locally in the use of aerial photographs, and encouraging results were obtained in a series of controlled experiments in the artificial precipitation of rain at Kongwa, using the silver iodide technique.

Virginia tobacco trials at Urambo were encouraging, both as regard the growth and health of the plants and the quality of the leaf from the barns. Cotton trials in all three regions showed fair to good growth, but 'stainer' attack threatens to be an economic problem. Encouraging results were obtained in trials of several varieties of rice on thirty acres at Urambo. At Kongwa the 1949-50 harvest yield per acre was $244 \mathrm{lb}$. shelled groundnuts, $99 \mathrm{lb}$. cleaned sunflower and 1,085 lb. shelled maize.

The Scientific Department continued to work on lines laid down in previous seasons, but little detailed work on sunflower was conducted in 1949-50 and 1950-51, since until a self-pollinating type can be developed which is also dwarf, drought-resistant and uniform for combining, other agronomic work on this crop is of little significance. At Urambo a system of so-called 'broad lands' has been developed which holds much promise for control of surface 'wash', an insidious and very serious cause of reduced yields, and this system is to be applied more generally in experimental work. The classification of soil types at Kongwa and in the Southern Province was completed for practical purposes.

Soil fertility studies in 1949-50 showed widespread and important phosphate deficiencies in most soils of the Southern Province and confirmed the general phosphate deficiency of the Kongwa soils. The principal plant-food deficiency at Urambo is nitrogen. This deficiency was more prominent in 1950-51 and may be expected to increase unless remedied by agricultural practice, such as adoption of measures to check the mineralization and leaching of nitrogen.

Work on soil-borne diseases has shown the presence at Urambo and in the Southern Province of Sclerotium rolfsii, a very serious disease of groundnuts and other crops in South Africa, although the incidence is at present small. The main plant disease with which the Department is concerned continues to be the rosette disease of groundnuts, and detailed field studies have continued on the biology of the aphis vector and its relation with predators, and on the carry-over of the disease in dry-season volunteer groundnuts. The use of systemic insecticides for controlling secondary multiplication of aphides is also being studied. A valuable degree of control of termite attack on standing crops has been obtained experimentally by the use of 'Gammexane', placed near the seed, as a soil fumigant.

The Operational Research Unit continued to work along the broad lines described in the annual report for 1949-50, and a new digger-lifter-windrower and a new spray winch were developed. The East African Scientific Committeo met twice during the year. 